\title{
Windcatcher as a Persian Sustainable Solution for Passive Cooling
}

\author{
Payam Nejat ${ }^{1,2 *}$ and Fatemeh Jomehzadeh ${ }^{3}$ \\ ${ }^{1}$ Faculty of Civil Engineering, University Technology Malaysia (UTM), Malaysia \\ ${ }^{2}$ Advanced Building and Environment Research (ABER) center, UK \\ ${ }^{3}$ Department of Environmental Engineering, University Technology Malaysia (UTM), Malaysia
}

Submission: June 02, 2018; Published: July 19, 2018

*Corresponding author: Payam Nejat, Faculty of civil engineering, University Technology Malaysia (UTM), Malaysia, Advanced Building and Environment Research (ABER) center, UK, Email: payam.nejaat@gmail.com

\begin{abstract}
Currently, building energy consumptionhas become an international issue especially in developing countries. In hot arid climate, $60 \%$ of total building energy consumptionin this areais associated with cooling systems. Wind as an important renewable energy can play a prominentrole to supply natural ventilation inside the building and windcatcher as a traditional technique can be implemented for this purpose. In this paper the different types of windcatchers, its performance and functionwas reviewed. It can be concluded in most area this technique can be successfully be employed and help to reduce fossil energy consumption and related $\mathrm{CO}_{2}$ emissions.
\end{abstract}

Keywords: Badgir; Passive Cooling; Natural ventilation; Windcatcher

\section{Introduction}

In most of countries, the per capita energy utilization has been significantly raised particularly in the developed countries. Recently, in developing countries energy consumption increased and has high level which is as a result of general growth in different segments like transportation, residential, commercial, and industrial developments.

Therefore, it is essential to think through new degrees and methods to energy preservation in both developed and developing countries for building sector. Conservation of energy is explained as practical method in energy consumption without influencing the standard of occupants living in house $[1,2]$.

Huge electricity consumption (particularly for cooling) has made trouble during peak hours to response to demand for many countries.

This enormous capacity building, which is completely dependent on fossil fuels, will encounter many countries with environmental threats and destructive effects on climate, rare water resources, land and air [3].

However, sustainable approach, which is one of the ways that can contribute in reduction of energy and $\mathrm{CO}_{2}$ emissions, emphasizes on utilization of local resources and passive approaches instead of active which use fossil fuels [3].
Energy efficient buildings' design is currently a noticeable subject on account of the energy costs growth, environmental influences and energy consumption, particularly for global warming.

In fact, in many countries, research studies on efficient building design are growing rapid and commercial and residential buildings must include enhancements on energy saving policies [4-6].

Natural ventilation is one of energy efficient methods which canbe addressed in sustainable design to decrease overall consumption in buildings. In this paper windcatcher (as one type of natural ventilation methods) will be reviewed briefly in types performance, function and analysis.

\section{Different Type of Natural Ventilation}

In natural ventilation the initial force to cause the ventilation is the wind which is an important renewable resource. The natural ventilation techniques can be divided to three types as followings:

\section{Window opening or vents}

This type forms the simplest one of natural ventilation. Via appropriate arrangement of openings, the enough current of natural ventilation can be achieved inside the building to decrease needs of conventional cooling. 
Joined with windows, vents also can be used in designed position where windows are not needed. Since this technique is economic option, various experimental and numerical studies have been done.

\section{Atria and courtyards}

Courtyard which can be seen in many regions has been an impactful method to supply natural ventilation for thousands of years for mankind across the world.Courtyards provide a relatively enclosed area to channel and direct airflow to some openings and cause convective natural ventilation inside and nearby the buildings.

Different investigations generally admit that the winddriven ventilation can be raised by application of courtyard and atria but mostly efficient for low rise buildings. Nonetheless, the passive nature of this method shows that its efficiency depends basically on the existence of its driving forces.

\section{Windcatcher}

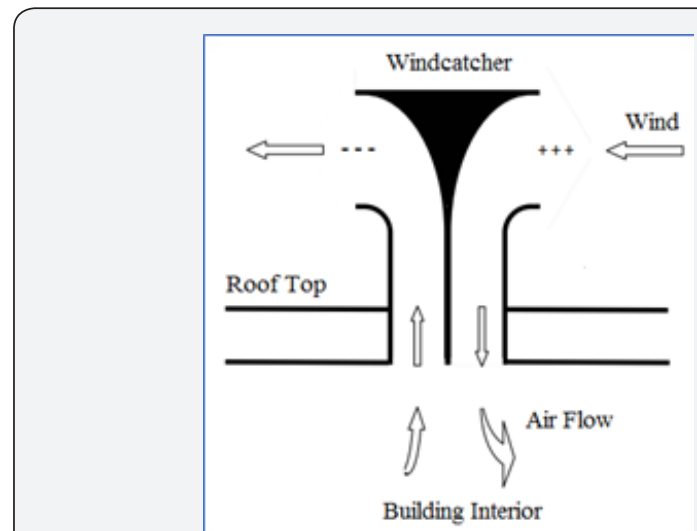

Figure 1: Wind effect on Wind-catcher [13].

One of the conventional systems for providing natural ventilation inside the buildings without utilization of conventional energy is windcatcher. Over three thousand years, people in Middle East used the windcatchers for many buildings. They are known by various names like Badgir, Malghaf, etc. in different areas of this district.

Windcatcher is usually a tall construction which has height between 3 and $33 \mathrm{~m}$ placed on the building roof (Figure 1). The windcatcher design traditionally depended on the social condition and wealth of house landlords, architects' personal experience as well as, and differed in the height of tower, number and position of openings, cross-section of the air channels, and tower position with attention to the structure [7-12].

\section{Types of Windcatcher}

In terms of external shape, it is generally considered two main categories for wind catcher including unidirectional and multidirectional wind catcher. The former also called one-sided wind catcher and the latter is classified under three sorts: two, three and four-sided wind catcher which usually have square plan, hexahedral and octahedral wind catcher.

\section{One-Sided Windcatcher}

Many countries of the Middle East enjoyed unidirectional windcatcher for those houses settling in regions which have a permanent prevailing wind. The performance of this system is mostly dependent upon the wind direction.

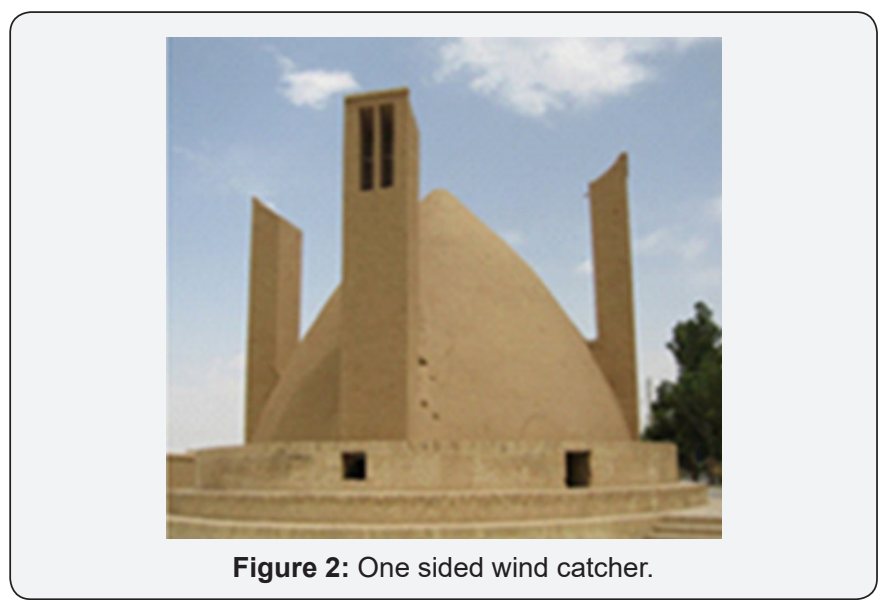

In other words, if there is an unfavorablewind directions, one-sided windcatcher will not well function. Hence, inlet openings of windcatcher should be at as much as high level to enjoy stack effect (buoyancy effect) like a solar chimney function for that special condition. Figure 2 depicts the structure of onesided windcatcher, the wind goes in from the single opening and passes via the living space and leaves the exhaust vents, doors, and windows.

\section{Two-Sided Windcatcher}

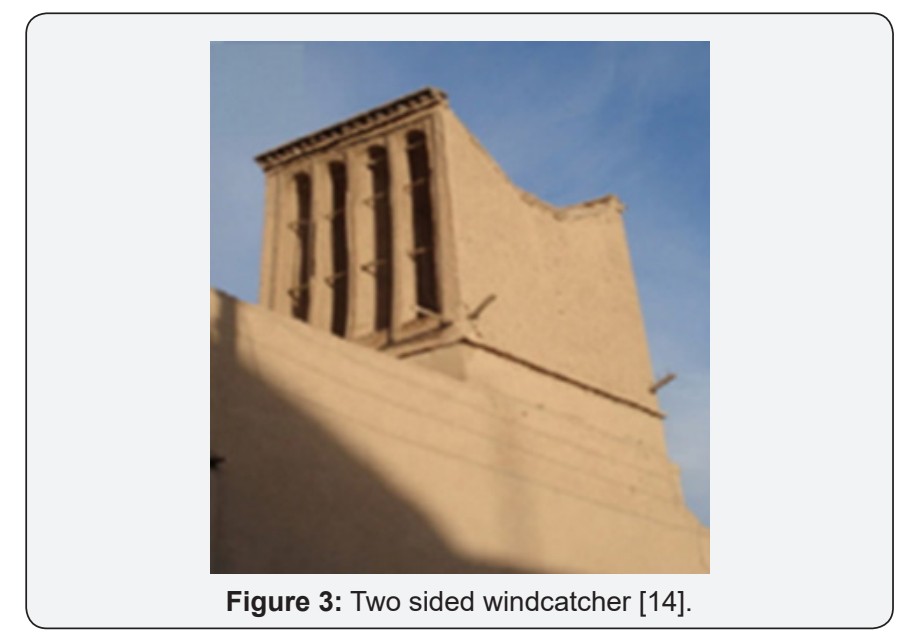

In regions with strong predominate wind, two-sided wind catcher is generally utilized which have two vents and two distinct underneath halves. Figure 3 shows the bidirectional wind catcher is separated into two channels in order to supplying (suction) and extraction of air flow.

The incident angle is the principal advantage of this device compared to one-sided windcatcher in which the unidirectional tower opening exposed under the transition angle and the airflow rate through it tends to zero [8-14]. 


\section{Three-Sided Windcatcher}

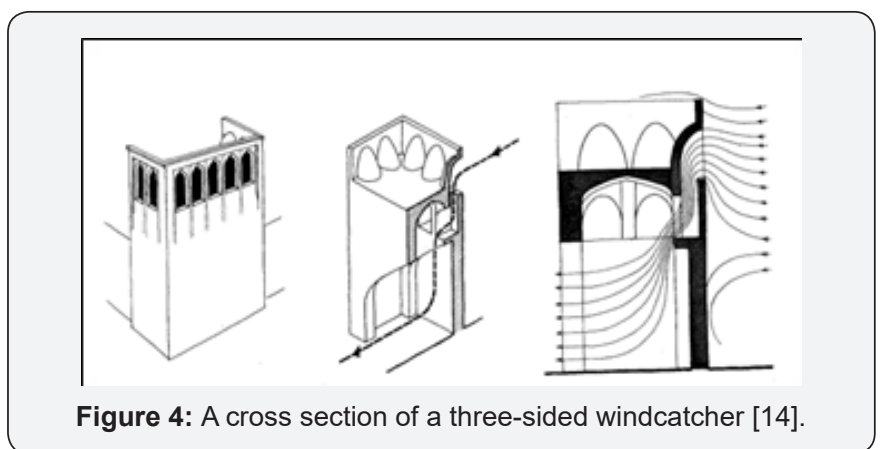

Figure 4 illustrates the three-sided wind catcher which often has larger windward side with more openings to capture as much predominant wind as possible. When air flow enters through the wind catcher, air velocity increases owing to curved form of openings.

\section{Four-Sided Windcatcher}

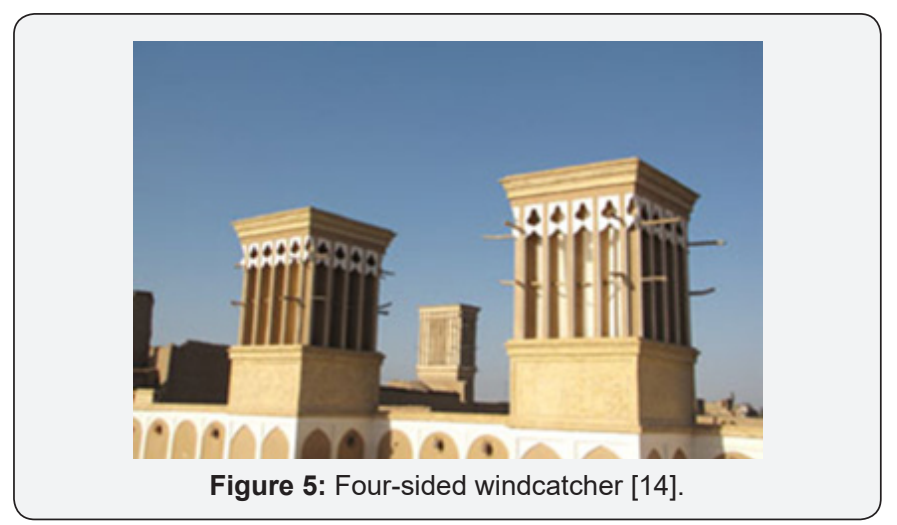

Based on previous studies, an abundance of four-sided windcatcher is more than other types of this system in the Middle East. In areas where there is no specific direction for wind, foursided windcatcher can be seen; therefore, its design is mainly dependent upon capturing the wind from all directions. Foursided windcatchers with decorations belong to a famous family's house in the city of Yazd, Iran as shown in Figure 5 [8].

\section{Hexahedral and Octahedral Windcatchers}

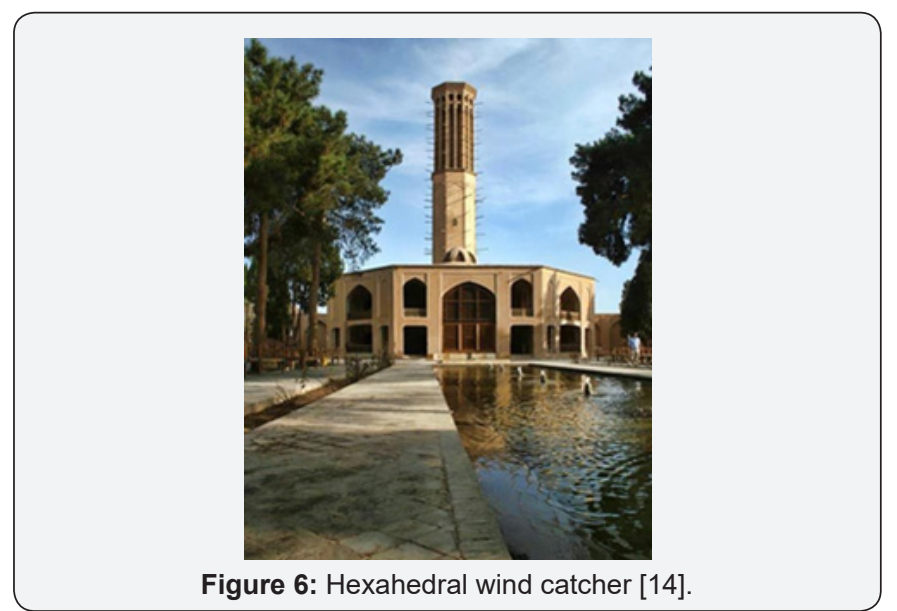

These types of windcatchers have been usually seen with regular multifaceted plans and they were designed in the shape of hexagon or octagon. Generally, they are higher than other windcatchers, especially eight-sided windcatcher; therefore, they will have more stability against wind pressure as well as tower form causes passing air flow with lower pressure.

The utilization of six-sided windcatchers is limited in the world, however some of them are found as water-reservoirs in Iran. Figure 6 shows the tallest traditional windcatcher of the world with octagonal plan and approximately 40 meters high, which places in a famous garden (DolatAbaad) in the city of Yazd, Iran [8].

\section{Function and Performance of Windcatcher}

Windcatcher's performance is based on the natural ventilation with implementing both stack effect and wind driven ventilation. There are two principal functions of windcatcher: the first is to related to opening which should bring in fresh air inside the building and second related to exit of windcatcher which should remove hot and polluted air of inside the building (the suction functions) and thus works such as a sucked and ventilation system [9-11].

The windcatcher function can be explained by the fact a flow from positive pressure to negative pressure causes the ventilation. According to this fact, in windcatcher, the opening in the wind direction absorbs the air into the building inside and the inside air with negative pressure depart from the exit of the windcatcher (Figure 1).

\section{Analyzing Methods for Windcatcher}

Computational Fluid Dynamics (CFD) is widely used for studying windcatcher performance. The CFD models consist of RANS (Reynolds Averaged Navier-Stokes equation) modelling and LES (Large Eddy Simulation). The conservation equation of permanency, energy, momentum, and concentrations of chemical-species can be solved by RANS modeling [12].

An overview of applications of ventilation indicated that CFD is the most popular tool used to assess the ventilation systems including windcatcher. CFD has become a reliable tool for the analysis of flows, heat transfer for any kind of ventilation and cooling systems. With results of CFD software the performance and efficiency of windcatcher can be assessed and easily can study temperature distributions, air velocity, humidity, $\mathrm{CO}_{2}$ concentration, thermal comfort etc [13].

To validate the results wind tunnel experiment is done. The wind tunnel can extract the air velocity, pressure coefficient, and air flow directions $[14,15]$.

\section{Conclusion}

In recent years attention toward wind energy as a green source for natural ventilation has been drawn. Natural ventilation 
has different types which windcatcher is one of the most effect ones. With respect to hot arid climate conditions in most of the country there is high potential to implement the windcatcher. Windcatcher can reduce temperature and provide fresh air for occupants as well as reduction in $\mathrm{CO}_{2}$ concentration inside the building. Windcatcher has different types which everyone is suitable for a specific condition. This old traditional technique can be merged with new building designs to raise the green concept in the building sector.

\section{Acknowledgment}

The authors would like to acknowledge the support of Advanced Building and Environment Research (ABER) center.

\section{References}

1. Hunt VD (1982) Handbook of conservation and solar energy, trends and perspectives. Van Nostrand Reinhold Company, p. 3-21.

2. Barbosa, Rogério Marcos, Nathan Mendes (2008) Combined simulation of central HVAC systems with a whole-building hygrothermal model. Energy and Buildings 40(3): 276-288.

3. IEA (2013) CO2 Emissions from Fuel Combustion 2013 Edition. International Energy Agency (IEA); 2013.

4. Holm A, Kunzel H, Radon J (2002) Uncertainty approaches for hygrothermal building simulations-Drying of AAC in hot and humid climates. In: Proceedings of the Buildings VIII Conference.

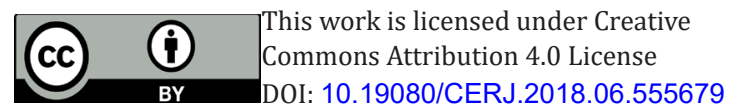

5. EIBI (2000) Commercial offices energy consumption leaps ahead energy in building and industry, p. 4.

6. Nicolas Mazzeo (Eds.) (2011) Chemistry, Emission Control, Radioactive Pollution and Indoor Air Quality, Publisher: In Tech, p. 692.

7. Phuoc Huynh (2010) A Report on the Wind Catcher. University of Technology, Sydney.

8. (2010) Application of computational fluid dynamics to the study of designed green features for sustainable buildings, Mak, Cheuk-ming, In Tech Open Access Publisher, pp.420.

9. Hanan M. Taleb, Steve Sharples (2011) Developing sustainable residential buildings in Saudi Arabia: A case study, Applied Energy 88(1): 383-391.

10. IEA (2018) International Energy Agency (IEA), Statistics.

11. Alhaji Mohammed, Ismail Mohammad Budaiwi (2013)Strategies for Reducing Energy Consumption in a Student Cafeteria in a Hot-Humid Climate: A Case Study 1(1): 14-26.

12. Engström A, Andersson L-O. Energy storage in concrete slabs reduce energy consumption and peak cooling loads at no increase in capital costs.

13. N Mendes, RCLF Oliviera, GH Santos (2003) Domus 2.0: Awhole building hygrothermal simulation program, Building Simulation 2003, Eindhoven, The Netherlands.

14. Fereshteh Tavakolinia (2011) WIND-CHIMNEY, Integrating the Principles of a Wind-Catcher and a Solar-Chimney to Provide Natural Ventilation. Master Dissertation, California Polytechnic State University, US.

\section{Your next submission with Juniper Publishers} will reach you the below assets

- Quality Editorial service

- Swift Peer Review

- Reprints availability

- E-prints Service

- Manuscript Podcast for convenient understanding

- Global attainment for your research

- Manuscript accessibility in different formats

( Pdf, E-pub, Full Text, Audio)

- Unceasing customer service

Track the below URL for one-step submission https://juniperpublishers.com/online-submission.php 